\title{
Ubuntunet Alliance: A Collaborative Research Platform for Sharing of Technological Tools for Eradication of Brain Drain
}

\author{
http://dx.doi.org/10.3991/ijet.v7i4.2285 \\ J. Mbale1, Z. D. Kadzamina ${ }^{2}$, D. Martin ${ }^{3}$ and V. Kyalo ${ }^{4}$ \\ ${ }^{1}$ University of Namibia, Windhoek, Namibia \\ ${ }^{2}$ Kamuzu College of Nursing, Lilongwe, Malawi \\ ${ }^{3}$ TENET, Cape Town, South Africa \\ ${ }^{4}$ KENET, Nairobi, Kenya
}

\begin{abstract}
The UbuntuNet Alliance Alliance is well-placed to facilitate interaction between education and research institutions and the African academic and researcher in the Diaspora so that together they can strengthen research that will exploit new technological tools and increase the industrial base. It is envisaged that the Alliance will become an important vehicle for linkages that will facilitate repatriation of scientific knowledge and skills to Africa and even help reduce and eventually eradicate the brain drain which has taken so many excellent intellectuals to the developed world. As organisational vehicles for inter-institutional collaboration both established and emerging NRENs can play a critical role in reversing these trends and in mitigating what appears to be the negative impact of the brain drain.
\end{abstract}

Index Terms - Brain drain, Diaspora, NREN, UbuntuNet Alliance.

\section{INTRODUCTION}

This paper starts from the generally accepted definition of brain drain as entailing the emigration of a significant proportion of a country's highly skilled personnel to other countries that offer better professional, economic and social opportunities. African professionals who migrate to Western Europe and North America seem to be dissuaded from returning home by the economic and political crises that have bedeviled the African continent for decades. Some of the factors behind this trend include failing economies, high unemployment rates, human rights abuses, armed conflict and inadequate social services.

The paper recognises brain drain as a problem which is amenable to reversal and argues that the UbuntuNet Alliance for Research and Education Networking is strategically placed to assist in resolving the problem by providing a platform for interaction between professionals at home and those in the Diaspora.

The UbuntuNet Alliance [1] is a non-profit association that gives legal and operational substance to the collaboration between National Research and Education Networks (NRENs) in the sub-Saharan region in the securing of broadband connectivity. It acts as a consortium for the acquisition of bandwidth for established and emerging National Research and Education Networks in Africa and seeks to interconnect them with NRENs outside the continent via a pan-African high speed backbone network. The Alliance aims to acquire significant bandwidth connectivity at affordable prices for the NRENs throughout Africa. Initially its backbone development strategy envisages two clusters: the UbuntuNet East Backbone Development Cluster and the UbuntuNet South Backbone Development Cluster.

It is through these backbone clusters, and new ones to be established, that the Alliance can play a vital role in addressing the issue of brain drain from Africa. It is anticipated that this will be achievable through its developmental vision of a collective research and education backbone, of acting as a consortium for bargaining for very high speed connectivity in gigabits per second, and provision of auxiliary services, access to optical fibre, and coordinating a major thrust to connect African NRENs to the Géant network in Europe which serves as the central hub of interconnected RENs of the world.

\section{Statement of THE Problem}

In most of sub-Saharan Africa industries have remained largely static due to lack of both innovation and invention of new technological tools for production. It is apparent that not many African universities are in a position to spearhead the research that is required to provide the tools to drive these industries. While student numbers have increased investment in institutional infrastructure, such as science laboratories and workshop equipment required by science-based faculties, has been very limited. In addition, research and education networks do not yet exist in many sub-Saharan African countries. Few African universities have Internet connections of more than two or three megabits per second, which is completely inadequate to allow staff and students to participate in today's dataintensive scientific research milieu.

The upshot is that African academics, especially in science and technology, face a fundamental and dramatic choice. They either remain at home or seek "greener pastures" abroad. The choice to stay at a university in Africa entails acceptance of a role that is primarily educational and developmental as well as recognition that participation in open scholarly and research activity will be a tough struggle against unfair odds. While many 
academics do remain and perform valuable services in their universities, others feel that they have no option but to become part of the brain drain from Africa. Those who leave are primarily motivated not only by the opportunity to make ends meet but also by the prospect of participating at the cutting edge of research and scholarship as they work with colleagues at the frontiers of knowledge.

By contrast in the Western World, the research done in universities has fuelled economic development. The American model is illustrative. Among University leaders who established a vibrant partnership between universities and the US military more than sixty years ago was Vannevar Bush [2], in his capacity as the American science advisor. According to [3] a report of President Clinton's Council of Economic Advisers called "New Growth Theory" states that nearly half of the growth in the American economy in the last 40 years has been due to investments in research and development carried out by universities and research centres. He summarises recent statistics as showing that $73 \%$ of the papers cited by U.S. industry patents are based on publicly supported science, authored principally by academic scientists, the remainder being authored by scientists employed outside academia [3]. While the American experience would be hard to emulate the fact remains that research carried out in American universities and research institutions enhanced the growth of US industries and created more job opportunities for both citizens and foreigners.

\section{RELATED WORK}

Several studies, which are probably cited in other presentations, have raised various issues about the brain drain from Africa and provided statistics of educated people who have left the continent for the Western World in search of improved career and life-style opportunities. However, it seems very little of practical significance about the retention of the professional workforce has been discussed or implemented. Naturally the answers are to be found among the very reasons that attract African brains to other countries.

According to [4] the International Organisation for Migration has estimated the number of teachers, engineers and doctors leaving Africa every year at twenty thousand. He further states that although the continent needs one million engineers and scientists for its development, most countries have not been able to prevent the exodus perhaps the worst case scenario being Nigeria's estimated forty thousand graduates in the Diaspora [1]. In [5] he has estimated that among the immigrants accepted for settlement in Britain the contribution of Africa and Asia, other than the Indian sub-continent, is $30 \%$ each; that of the Indian sub-continent is $16 \%$; Europe, $12 \%$; and the Americas, 8\% [5]. From this statistical comparison, Africa's share per capita is exceedingly high considering that Asia has a very much higher population.

The cumulative effect of the brain drain has been to exacerbate the dependency syndrome as Africa has paid dearly to attract expatriates to take up strategic positions. A US Congressional Research Service report estimates that Africa has paid $\$ 1.2$ billion for expatriates who were recruited to replace sixty thousand African professionals who emigrated between 1985 and 1990.

The need to reverse the brain drain has been reaffirmed under the NEPAD Framework and Action Plan. Specific initiatives include the UNESCO-Hewlett Packard partnership project in selected African countries whose development has been hampered by the loss of highly skilled personnel [6]. The project will promote two strategies. The first is the creation of linkages and networks among experts in the Diaspora and those in the home country. The second strategy entails mobility schemes under which professionals will relocate to their home countries for short term teaching and research assignments. In both instances UbuntuNet Alliance will be in a position to facilitate efficient and effective connectivity on a global scale especially where such networks are developed within NRENs.

\section{REVERSING THE IMPACT OF BRAIN DRAIN}

Different interventions by various parties are needed to slow down and eventually reverse the brain drain from Africa. One of the most effective strategies is to create networks of professionals and intellectuals through which the knowledge and skills of those based overseas can be tapped without requiring them to relocate. The South African Network of Skills Abroad (SANSA) is an example of a virtual organisation that invites professional South Africans to sign up on its website. SANSA reports that it has remained in touch with at least 22,000 graduates from five major South African universities who are resident abroad mainly in Australia, United Kingdom and United States. For instance it has been estimated that 30 per cent of contactable doctorates of the University of Cape Town living overseas comprise significant proportions of the University's graduates in commerce, education, engineering and medicine [7].

The rest of this paper focuses on infrastructural interventions that help to nullify the effects of geographic isolation of Sub-Saharan universities and research centres from each other and from other centres worldwide. Specifically, we stress the importance of modern, Internetbased communications nationally and regionally, and especially of "research and education networking", as practiced in Europe and North America, in enabling the staff and students at the universities and research centres of Sub-Saharan Africa to participate as peers of and collaborators with researchers everywhere in the academic and research life.

There can be no doubt that if African academics could interact remotely with other academics, with educational and research databases and with research instruments world-wide as readily as most academics at European and American universities can, then many more African academics would elect to stay at or return to their home institutions and take pride in playing the dual role of teacher and active researcher. There can also be no doubt that such improvements in the national and regional electronic communications infrastructure, and of staffing and activities within the universities, would dramatically stimulate economic development and raise the demand for professionals and skilled labour generally.

\section{DEVElopments In THE COMMUNICATIONS INDUSTRY}

The pace of development of the communications infrastructure is accelerating in many countries of Sub-Saharan Africa. The extraordinary growth of mobile telephony shows that the African giant has awoken, and in several countries mobile operators have grown to become effec- 
tive alternative service providers and serious challengers to the established and over-protected incumbent telecommunications operators. New optical fibre cables are being deployed not only by telecommunications operators but also by electricity companies along their power lines, by gas companies along gas pipelines and by railways along railway lines.

These advances in infrastructure have also accelerated development of communications services to end customers. In particular commercial Internet service providers compete with each other in many countries. National Associations of Internet Service Providers have been formed in several countries as well as a regional association of African Internet Service Provider Associations, known as AfrISPA [8]. With support from DFID, IDRC and OSI, the Association has successfully fostered the creation of operational Internet Exchange Points as well as the formation of national Internet Service Provider Associations. A key role of each national association is to actively lobby for and foster the leveling of the playing field as regards telecommunications regulations and curtailing unfair competition from incumbent telecommunications operators.

In other words African governments should move away from nurturing the market power and financial interests of incumbent telecommunications operators and, instead, promote the growth of efficient electronic communications industries. This should be done at all levels from the deployment and operation of infrastructure, including cross-border international connectivity, to the provision of communications services to end-customers. Removal of such protectionist policies will in turn spur economic development - the main tonic for reversing the brain drain.

\section{RESEARCH AND EDUCATION NETWORK}

\section{A. General Remarks}

"Research and education networking" refers to the organised inter-connection, at very high bandwidths, of campus networks of universities and research institutions, nationally, regionally and globally. Many countries in the developed world have established National Research and Education Networks (NRENs). At the continental level, NRENs in Europe, North America, Canada, Latin America and the Far East have formed so-called regional research and education networks: Géant in Europe, Abilene and NLR in the USA, CANARIE in Canada, RedClara in Latin America and TEIN2 in the Far East. These regional RENs inter-connect with each other to form a single interconnected global research and education network.

The policies and practices of research and education networking are very well established in most countries and regions of the World. A key element is compliance with and respect for each others' Acceptable Use Policies (AUPs) that delineate what kinds of institutions may connect and for what purposes. Commonly, use of the network or services for commercial purposes is prohibited.

Organisationally, research and education networking is controlled and managed at the institutional campus network level; at the national level where responsibility and initiative lies with the NREN, and at the regional and global level, where responsibility and initiative lies with regional RENs to establish regional backbones that interconnect the national RENs of the region, and to interconnect regional backbones to each-other as part of the global REN.

\section{B. NRENs in sub-Saharan Africa}

Research and education networking in Sub-Saharan Africa is dramatically under-represented, but the region has started moving decisively to remedy this position. In doing so, it has many friends and supporters, and the REN community worldwide will welcome Africa's rise to parity as regards connectivity for its universities and research institutions.

In Sub-Saharan Africa six NRENs are operational in the sense that they are delivering services to their member institutions [1]. But there is a flurry of activity to form NRENs in several other countries, the most recent being TERNET in Tanzania, bringing the total to seven and ZAMREN as a Zambian NREN "in construction". At a workshop for emerging NRENs held on 22 February 2007 in Nairobi, fourteen countries of Central, Eastern and Southern Africa were represented. This activity is spurred on by the accelerating deployment of optical fibre networks and the prospect of new submarine cables being laid along the eastern seaboard of African, including the so-called EASSy cable system and others. In some countries, the NREN is being formed through a project run by a government department, and in others, as a nongovernmental association of universities and research institutions.

\section{Formation of Ubuntunet Alliance}

Established and emerging NRENs in Kenya, Malawi, Mozambique, Rwanda and South Africa came together in the latter half of 2005 to found a new regional research and education network: the UbuntuNet Alliance for Research and Education Networking. The UbuntuNet Alliance is driven by a vision of securing high bandwidth connections - gigabits instead of the current kilobits per second - at affordable prices, that connect African NRENs to each other, to other NRENs worldwide, and to the Internet generally [1]. The UbuntuNet Alliance will not normally be involved in development of specific campus networks. At the national level, the Alliance promotes the establishment of NRENs as organisational entities and collaborates with NRENs in securing access to optical fibre infrastructure.

At the regional level, the Alliance will deploy crossborder links to inter-connect member NRENs, recognising that each NREN may have to transit traffic to and from other NRENs as part of the collaborative enterprise. The Alliance's strategy for gaining access to optical fibre infrastructure is opportunistic. At present development is focused on eastern and southern "clusters" of NRENs. The Alliance has invited the West African university and research community to propose a west "cluster" project.

\section{Terresterior Inter-connectivity Between NRENS}

Many if not most tertiary institutions depend on VSAT communications, which is very expensive. It is with this view that the UbuntuNet Alliance will secure terrestriallybased communications through the Sub-Saharan NRENs of the, by establishing at least two initial sub-regional backbones, which the Alliance calls "clusters". These are the UbuntuNet East Backbone Development Cluster 
(UEBDC) and the UbuntuNet South Backbone Development Cluster (USBDC).

The UbuntuNet East Backbone Development Cluster (UEBDC) is conceived to include those countries that have potential terrestrial links and access to the proposed EASSy or other submarine cable with landings on the East African coast. This cluster includes the following countries: Ethiopia, Kenya, Rwanda, Sudan, Tanzania, Uganda and Zambia and has potential options for broadband terrestrial connectivity to Europe via submarine cable landing points in Mombasa and Dar-es-Salaam, or through Sudan and Egypt.

The UbuntuNet South Backbone Development Cluster (USBDC) comprises those states that have or will soon have broadband connectivity to the SAT-3 submarine cable landing point at Melkbosstrand, near Cape Town, South Africa. Initially, the USBDC includes the following countries: Botswana, Mozambique, Namibia, South Africa, Lesotho, Swaziland, Zambia, Malawi, Zimbabwe and Tanzania. The USBDC will also enjoy broadband connectivity to the rest of the world through Mtunzini, north of Durban, via the South Africa Far East (SAFE) submarine cable, to Penang, Malaysia, and hence, across the Pacific Ocean to the west coast of the United States of America. Further options will be available when the proposed EASSy cable, incorporates landing points in Mtunzini, Maputo and then northwards via Dar es Salaam, Mombasa to Port Sudan, where it will connect to existing northern hemisphere cable systems.

Finally, at the global level, the UbuntuNet Alliance will provide connectivity for its member NRENs to global REN via the best means available. For the eastern cluster, this entails VSAT links for the immediate future, but with the prospect of submarine connectivity via one of several projects that envisage laying a cable along the east coast of Africa. The southern cluster will use the existing SAT3 submarine cable, and also, potentially, have access to future east coast and west coast submarine cable systems. These strategies are discussed further below [1].

Of course, this hierarchical picture is simplistic, especially as it ignores the reality that many campus networks cannot connect to other campus or research networks because they lack available communications infrastructure. Such institutions have little choice but to procure Internet connectivity from a satellite provider, and to accept that all traffic that passes between the campus and any other network, will traverse an expensive, highlatency satellite circuit and pass through the provider's teleport in Europe or elsewhere outside Africa. The UbuntuNet Alliance will attempt to provide useful services to such institutions, in collaboration with whatever NREN to which they will eventually be able to connect. The "Thrust to connect to Géant", which is described below, is one such service.

\section{E. Thrust to Connect to NRENS of Africa to Geant of Europe}

The UbuntuNet Alliance has established connectivity to Géant for its member NRENs, using the NREN's existing service contracts and infrastructures, including both terrestrial and satellite-based infrastructures. This thrust focuses on IP routing arrangements to connect RENs via UbuntuNet to Géant without waiting for broadband transport infrastructures to become affordable or available. The bandwidth of the connectivity is determined by the institutions' and NRENs' existing infrastructure, and, in many cases, would not be at broadband speeds. With assistance from DANTE, the company that operates Géant, and using a router donated by CISCO Systems, the Alliance has established a connection to Géant from an UbuntuNet Hub in London. The South African NREN, TENET connects directly to the UbuntuNet Hub, while, the Kenyan NREN, KENET, connects via a GRE tunnel through the networks and its UbuntuNet's upstream commodity Internet Service Providers. Other member NRENs are expected to connect in the near future. For many NRENs, the long-haul connectivity from Africa involves transmission segments via satellites.

\section{F. Capacity Bulding Through Provision of Auxiliary Sevices}

The UbuntuNet Alliance intends to provide auxiliary services to its member NRENs. These services will include inter training programmes, such as Network Administration, Network Cabling, Network TroubleShooting, e-learning Content, Resource development and bandwidth management among Sub-Saharan institutions. Having carried such training, the Alliance would be in better position to deploy the skilled personnel to those NRENs that may lack skilled experts in particular areas.

\section{CONCLUSION}

This paper has attempted to stress the importance of modern, Internet-based research and education networks as a platform that can be used to bridge the gap between professionals in African universities and research centres and their counterparts in the Diaspora. As more African academics interact with others worldwide, and as they access educational and research databases globally, they will be encouraged to remain in their home institutions. Where professionals in the Diaspora are reluctant to relocate they will at least share their knowledge and skills through NRENs.

UbuntuNet Alliance provides the ideal platform to bridge the communication divide between scientists and other professionals at home and in the Diaspora. It is in this respect that UbuntuNet Alliance can play a vital role in the development and operations of national and regional research and education networks.

In particular the Alliance forms a continental bandwidth consortium that bargains for cheaper or affordable bandwidth for the institutions. The potentially massive terrestrial connectivity of UEBDC and USBDC would create more jobs for the nationals along the areas where the cable is laid.

It is most likely that significant changes and improvements in national and regional electronic communications infrastructure will eventually stimulate economic development and raise the demand for professionals and other skilled personnel which, in turn, will help to reverse the brain drain into brain gain.

The acquisition of adequate bandwidth will in turn facilitate efficient communication in various institutions and industries resulting in a positive impact on productivity and job creation. 


\section{REFERENCES}

[1] D. H. Martin, "What is UbuntuNet?" http://www.ubuntunet.net/ documents/What is UbuntuNet v6.pdf. 2007.

[2] V. Bush, "Science the Endless Frontier," A Report to the President, Director of the Office of Scientific Research and Development, US Government Printing Office, July 1945.

[3] R. C. Atkison, "The Role of Research in the University of the Future," Tokyo, Japan (in The Pursuit of Knowledge: Speeches and Papers of Richard C. Atkinson, University of California Press.), 1997.

[4] C.V. Marie, "Preventing Illegal Immigration: Juggling Economic Imperatives, Political Risks and Individual Rights," Council of Europe, ISBN 10 92-871-5360-4, 2004.

[5] J. Salt, "International Migration and the United Kingdom," Report of the United Kingdom Sopemi Correspondent to the OECD, 2005.

[6] M. A. Walker, "Piloting Solutions for Reversing Brain Drain into Brain Gain for Africa,” IST Africa 2007 Workshop 10a.
[7] South African Network of Skills Abroad (SANSA), http://sansa.nrf.ac.za/Default.aspx?Instruction=About

[8] African Internet Service Provider Association, http://www.afrispa.org.

\section{AUTHORS}

J. Mbale is with the University of Namibia, Centre of Excellence in Telecommunications (CoE), Department of Computer Science, Private Bag 13301, Windhoek, Namibia (e-mail: mbalej@yahoo.com).

Z. D. Kadzamina is Kamuzu College of Nursing, Lilongwe, Malawi

D. Martin is with TENET of South Africa.

V. Kyalo is with KENET of Kenya.

This work was supported in part by Ubuntunet Alliance. Received, September, 18, 2012. Published as resubmitted by the authors 3 December 212 . 